\title{
Sexuality, Self-Esteem and Partnership Quality in Infertile Women and Men
}

\author{
Sexualität, Selbstwertgefühl und Beziehungsqualität \\ bei infertilen Frauen und Männern
}

Authors

Affiliations
T. Wischmann ${ }^{1}$, K. Schilling ${ }^{1}$, B. Toth ${ }^{2}$, S. Rösner ${ }^{2}$, T. Strowitzki ${ }^{2}$, K. Wohlfarth ${ }^{3}$, H. Kentenich ${ }^{3}$

${ }^{1}$ Institute of Medical Psychology, University Hospital Heidelberg, Heidelberg

${ }^{2}$ Gynaecological Endocrinology and Reproductive Medicine, Heidelberg University Women's Hospital, Heidelberg

${ }^{3}$ Fertility Center Berlin, Berlin

Key words
infertility
o sexual dysfunctions
partnership quality
self-esteem
confidence
Schlüsselwörter
Infertilität
- Sexualstörungen
- Beziehungsqualität
- Selbstwertgefühl
- Selbstvertrauen

received 13.2.2014

revised 17.4.2014

accepted 23.4.2014

Bibliography

Dol http://dx.doi.org/

$10.1055 / \mathrm{s}-0034-1368461$

Geburtsh Frauenheilk 2014; 74

759-763 @ Georg Thieme

Verlag KG Stuttgart · New York .

ISSN 0016-5751

\section{Correspondence}

\section{Dr. Tewes Wischmann}

University Hospital Heidelberg

Inst. of Medical Psychology

Bergheimer Straße 20

69115 Heidelberg

tewes.wischmann@

med.uni-heidelberg.de

\section{Abstract \\ $\nabla$}

Introduction: Infertile couples often report quality-of-life impairments, especially in terms of sexuality, self-esteem and partnership quality. So far, there have been no systematic studies of the sex lives and behaviour of infertile women and men before and after the emergence of their mutual desire for a child.

Materials and Methods: From February 2010 to August 2010 all couples starting treatment either at Heidelberg University's Women's Hospital or at the Fertility Center Berlin were asked to fill out the Self-Esteem and Relationship Questionnaire (SEAR). A total of $n=158$ women and $n=153$ men participated in the study.

Results: Decreasing tendencies were observable for both partners in the domains Sexual Relationship Satisfaction and Confidence and in the subscales Self-Esteem and Overall Relationship Satisfaction. There were especially clear indications of a loss of spontaneous sexuality during the experience of infertility. We were also able to establish that infertility has a negative impact on women's self-esteem.

Discussion: The results of this study indicate that SEAR can be used as a feasible instrument for identifying infertile women and men whose infertility has a negative effect on their relationship quality and/or sex lives.

\section{Zusammenfassung \\ $\nabla$}

Einführung: Infertile Paare berichten häufig von eingeschränkter Lebensqualität, insbesondere bezüglich ihrer Sexualität, ihres Selbstwertgefühls und ihrer Beziehungsqualität. Bisher gab es noch keine systematischen Studien zur Erfassung sexuellen Erlebens und Verhaltens infertiler Frauen und Männer vor und nach dem Auftreten ihres gemeinsamen Kinderwunschs.

Material und Methode: Zwischen Februar und August 2010 wurden alle Paare, die eine Infertilitätsbehandlung entweder an der UniversitätsFrauenklinik Heidelberg oder im Fertility Center Berlin begonnen hatten, gebeten, den „SelfEsteem and Relationship Questionnaire“ (SEAR) auszufüllen. Insgesamt nahmen $n=158$ Frauen und $n=153$ Männer an dieser Studie teil.

Ergebnisse: In den Bereichen „Zufriedenheit mit der Sexualität“ und „Selbstvertrauen“ sowie in den Subskalen „Selbstwertgefühl“ und „allgemeine Zufriedenheit mit der Beziehung“ waren bei beiden Partnern abnehmende Werte zu beobachten. Insbesondere gab es klare Hinweise auf die Abnahme spontaner Sexualität durch die Erfahrung der Infertilität. Wir konnten ebenso feststellen, dass Infertilität einen negativen Einfluss auf das Selbstwertgefühl der betroffenen Frauen hat. Diskussion: Diese Studienergebnisse weisen darauf hin, dass der SEAR als ein geeignetes Instrument zur Identifizierung derjenigen Frauen und Männer mit Kinderwunsch dienen kann, bei denen die Infertilität einen negativen Einfluss auf ihre Beziehungsqualität und/oder ihre Sexualität hat. 


\section{Introduction}

$\nabla$

Experience of infertility has a negative effect on most couples' personal lives [1], notably self-esteem in women [2] and the sexuality of both partners [3]. Many women report a decline in their sexual activities following the infertility diagnosis [4]. The results concerning men's sexuality in connection with infertility are inconclusive, but the majority of the studies showed that erectile dysfunctions and premature ejaculation are more common in infertile men undergoing ART (assisted reproductive technologies) than in the general population [5]. A recent review of 14 studies came to the result that men participating in ART have an increased rate of erectile dysfunctions, whereas reduced sexual desire is more prevalent in infertile than in fertile women [6]. The prevalence of sexual disorders in infertile couples remains unclear [7]. In the short term, partnership quality is also negatively affected by the diagnosis of infertility [8]. In this pilot study (a sub-study of [9]) we attempt to pinpoint with the aid of validated questionnaires (i) changes in sex life, self-esteem and relationship quality before and after the emergence of the desire for a child for both women and men and (ii) differences in these variables, if any, between women and men.

\section{Materials and Methods}

$\nabla$

\section{Study population}

For this pilot study, the authors approached all the couples coming to Heidelberg University's Women's Hospital and to the Fertility Center Berlin for first-time counselling on involuntary childlessness. From February 2010 up to and including August 2010 , all couples were asked before the first medical consultation to complete the questionnaires in the way described below. The design of the study and the selection of the questionnaires had been approved by the Ethics Committee of the Medical Faculty of Heidelberg University.

\section{Selection of the questionnaire}

Since studying sexuality is a sensitive issue, we were very scrupulous and thorough in our choice of questionnaires. Although widely used, the "International Index of Erectile Function" (IIEF [10]) for men and the "Female Sexual Function Index" (FSFI [11]) for women were felt to be too invasive and forthright and therefore unsuitable for our patient sample as we anticipated the risk that non-responder rates might be too high. We therefore decided to use the "Self-Esteem and Relationship Questionnaire" (SEAR [12]), which measures self-esteem and relationship satisfaction in addition to sexual satisfaction. This questionnaire was originally developed for men with erectile dysfunctions (ED). It consists of 14 items and contains 5 components: a Sexual Relationship Satisfaction domain (8 items; e.g. "I was satisfied with our sex life"), a Confidence domain including a Self-Esteem subscale (4 items; e.g. "I had good self-esteem") and an Overall Relationship Satisfaction subscale (2 items; e.g. "I was satisfied with our relationship in general"), finally an overall (sum) score. The two domains Sexual Relationship and Confidence resulted from the two-factor solution in the validation study's factor analysis [12]. The response options are 1 = "Almost never/never", 2 = "A few times (much less than half the time)", 3 = "Sometimes (about half the time"), 4 = Most times (much more than half the time)" and 5 = Almost always/always". Questions 8 and 11 are reverse- scored so that a higher score indicates a more favourable response for all 14 items.

\section{Evaluation of the SEAR}

Each domain score, subscale score, and overall score has to be transformed into a $0-100$ scale using the following equation: transformed score $=100 \times[$ (actual raw score - lowest possible raw score)/possible raw score range]. The transformed score 0 stands for least favourable response, 100 means most favourable response. In the original validation study for SEAR [12] involving 98 men with a clinical diagnosis of ED and a control group of 94 age-matched controls without ED, Cronbach's $\alpha$ values for the Sexual Relationship domain, the Confidence domain, and overall score were $0.91,0.86$, and 0.93 respectively. For the Self-Esteem and Overall Relationship subscales these values were 0.82 and 0.76 respectively. These values indicate (highly) satisfactory internal consistency reliability. An intervention study supported its validity as a measure of sexual relationship, confidence and particularly self-esteem [12]. No cut-off score for any sexual disorder is given by the authors of SEAR.

\section{Modification of SEAR items}

To assess the women's responses, two items of the original SEAR were modified in accordance with a procedure suggested by Nelson and co-workers [13]. Question 2 was rephrased as "I felt confident that during sex my arousal would last long enough", while question 10 was rephrased as "I felt like a whole woman". Another modification we made to the original SEAR questionnaire was to add to the items' time specification "During the past 4 weeks" (on the right-hand margin of the questionnaire layout) check boxes for the period "Time before my desire for a child" (on the questionnaire's left-hand margin) to help assess changes (retrospectively) in the questionnaire domains before and after the onset of the wish for a child.

As described previously [9], we also assessed basic socio-demographic variables like age, duration of partnership and infertility, profession. For organisational reasons, this assessment was only possible at the Heidelberg centre.

\section{Statistical analysis}

The evaluation of the responses was undertaken via frequency and percentage calculations, mean values and standard deviation and the $t$ test for dependent and independent samples with the aid of the statistics programme SAS 9.2. The factor analyses of SEAR (separately for women and men) are described below.

\section{Results}

$\nabla$

\section{Characteristics of the two study samples}

A total of 156 couples were approached in Heidelberg, the response rate was $55.8 \%$ for women $(n=87)$ and $54.5 \%$ for men $(\mathrm{n}=85)$. In Berlin, a total of 90 couples were approached. The response rates were $78.9 \%$ for the women $(n=71)$ and $75.5 \%$ for the men $(n=68)$ respectively. Since the Heidelberg part of this study was a sub-study of a previous one [9], we presume that the results of the responder/non-responder analysis there (which showed no selectivity in the study population) are also valid for the Heidelberg part of this study too. The testing of all SEAR domains and subscales for differences between the two study centres for women and men separately yielded no significant results (data not shown), so the two questionnaire samples were 
Table 1 Comparison of SEAR scores for women and men at two different time-points.

\begin{tabular}{|c|c|c|c|c|c|}
\hline \multirow[t]{3}{*}{ Domain/subscale } & M & SD & M & SD & $\mathbf{p}$ \\
\hline & \multicolumn{5}{|c|}{ Women ( $n=158)$} \\
\hline & \multicolumn{2}{|c|}{ Time before my desire for a child } & \multicolumn{2}{|c|}{ During the past 4 weeks } & \\
\hline Sexual Relationship Satisfaction & 81.89 & 1.04 & 73.80 & 1.40 & $<0.0001$ \\
\hline Confidence & 87.72 & 1.02 & 79.68 & 1.27 & $<0.0001$ \\
\hline Self-Esteem & 85.71 & 1.23 & 75.61 & 1.54 & $<0.0001$ \\
\hline Overall Relationship Satisfaction & 91.83 & 1.09 & 88.07 & 1.34 & 0.0012 \\
\hline \multirow[t]{3}{*}{ Overall Score } & 84.67 & 0.88 & 76.38 & 1.21 & $<0.0001$ \\
\hline & \multicolumn{4}{|c|}{ Men $(n=153)$} & \\
\hline & \multicolumn{2}{|c|}{ Time before my desire for a child } & \multicolumn{2}{|c|}{ During the past 4 weeks } & \\
\hline Sexual Relationship Satisfaction & 83.37 & 1.06 & 77.53 & 1.26 & $<0.0001$ \\
\hline Confidence & 88.46 & 0.96 & 85.86 & 1.25 & 0.0001 \\
\hline Self-Esteem & 87.17 & 1.17 & 84.27 & 1.39 & 0.0002 \\
\hline Overall Relationship Satisfaction & 90.96 & 1.10 & 89.03 & 1.35 & 0.0264 \\
\hline Overall Score & 85.77 & 0.85 & 81.12 & 1.14 & $<0.0001$ \\
\hline
\end{tabular}

$\mathrm{M}=$ mean; $\mathrm{SD}=$ standard deviation (domains in bold)

pooled ( $a$ total of $n=158$ women and $n=153$ men). In the Heidelberg part of this study, the women's' mean age was 34 years (mean age of the men: 37.5 years). The mutual wish for a child lasted for 2.7 years in average in this sample.

\section{Differences between SEAR scores before and after} the emergence of the mutual desire for a child

- Table 1 shows the scores of women and men and the decrease in the SEAR scores for all domains and subscales between the two time-points "Time before my desire for a child" and "During the past 4 weeks" for women and men separately. All differences were statistically significant. In terms of the individual items, the highest decreases at the second time-point were found for the items "I felt that sex could be spontaneous" (for both partners), "I felt confident" (for women) and "I felt relaxed about initiating sex with my partner" (for men).

\section{Differences between SEAR scores of women and men}

In all SEAR domains and subscales, the absolute values of the differences were higher for women than for men (statistically significant for Self-Esteem, Confidence and Overall Score). Especially on the subscale "Self-Esteem" these differences between women's and men's scores were conspicuous: ten points for women in contrast to about three points for men.

As for the differences between women and men, only the differences at time-point "During the past 4 weeks" in connection with Sexual Relationship Satisfaction $(p=0.049)$, Self Esteem $(p<0.0001)$, Confidence $(p=0.0006)$ and the Overall Score $(\mathrm{p}=0.0046)$ were statistically significant. The differences on the SEAR scales between women and men before the emergence of their mutual desire for a child were not statistically significant.

\section{Factor analyses of the SEAR}

As in the SEAR validation study [12], we calculated confirmatory factor analyses with oblique factor rotation (promax) for women and men separately. The scree test depicted a three-factor solution for both women and men ( $\bullet$ Table 2 ).

For women, the resulting factor 1 was named "Sexual Satisfaction", factor 2 "Confidence" and factor 3 "Relational Satisfaction". For men, factor 1 was named "Confidence", factor 2 "Sexual Functioning" and factor 3 "Sexual Well-Being".

\section{Discussion \\ $\nabla$}

Impact of infertility on women and men

The negative impact of infertility and of reproductive medicine treatment on the sexuality of couples is a well-known phenomenon in the fertility counselling sector. This study uses a validated questionnaire to pinpoint this effect. There were especially clear indications of a loss of spontaneous sexuality during the experience of infertility. Another factor that showed up clearly was that infertility has a negative impact on women's self-esteem. This is fully in line with clinical experience [1] and other research results [7]. The lower values in the two domains Sexual Relationship Satisfaction and Confidence as well as on the subscale Self-Esteem and the lower overall score for women (compared to men) may be the expression of the higher negative impact of infertility on women than on men. In the well-known and frequently cited study by Mahlstedt and co-workers [14], 49\% of the women but only $15 \%$ of the men rated infertility as the most upsetting experience in their lives. On the other hand, it seems fair to assume that women tend to recognise and express their emotions more easily than men [15].

\section{Comparison with other studies}

To the best of our knowledge, SEAR has only been used before to question infertile women and men in the study described in [13] and [16]. In that study, 121 couples presenting for the evaluation of infertility at two tertiary-care medical centres were investigated with SEAR and other questionnaires. The results are only partly in line with our findings. For women (in [13]), mean scores varied between 24 (on Self-Esteem) and 36 (on Confidence), whereas the male partners (in [16]) scored between 26 (on Overall Relationship) and 32 (on Confidence). These values are about 50 points lower than the findings for women and men in our study. In the case of the men, our results are very close to the sample of men without erectile dysfunction in the original SEAR validation study ranging from 74 (for Sexual Relationship Satisfaction) to 83 (for Self-Esteem) [12]. We have no genuinely satisfactory explanation for this discrepancy. The samples differed in some respects, given that the women and men in our sample were about two years older than the American sample and had been trying to achieve a pregnancy for a mean period of 2.7 years (compared to 2 years in [13] and [16]). It seems likely that the participants in our study may have responded more in line with 
Table 2 Results of the SEAR factor analyses for women and men.

\begin{tabular}{|c|c|c|c|}
\hline SEAR domains (subscales) & SEAR items (for women/men) & $\begin{array}{l}\text { Factor no. } \\
\text { women }^{\mathrm{a}}\end{array}$ & $\begin{array}{l}\text { Factor no. } \\
\text { men }^{\text {b }}\end{array}$ \\
\hline \multirow[t]{8}{*}{ Sexual relationship domain } & 1. I felt relaxed about initiating sex with my partner. & 1 & 3 \\
\hline & 2. I felt confident that during sex my arousal/erection would last long enough. & 1 & 2 \\
\hline & 3. I was satisfied with my sexual performance. & 1 & 2 \\
\hline & 4. I felt that sex could be spontaneous. & 1 & 3 \\
\hline & 5. I was likely to initiate sex. & 1 & 3 \\
\hline & 6. I felt confident about performing sexually. & 1 & 2 \\
\hline & 7. I was satisfied with our sex life. & 3 & 3 \\
\hline & 8. My partner was unhappy with the quality of our sexual relations. & 3 & 2 \\
\hline \multirow{4}{*}{$\begin{array}{l}\text { Confidence domain } \\
\text { (Self-esteem subscale) }\end{array}$} & 9. I had good self-esteem. & 2 & 1 \\
\hline & 10. I felt like a whole woman/man. & 2 & 1 \\
\hline & 11. I was inclined to feel that I am a failure. & 2 & 1 \\
\hline & 12. I felt confident. & 2 & 1 \\
\hline \multirow{2}{*}{$\begin{array}{l}\text { Confidence domain } \\
\text { (Overall relationship subscale) }\end{array}$} & 13. My partner was satisfied with our relationship in general. & 3 & 1 \\
\hline & 14. I was satisfied with our relationship in general. & 3 & 1 \\
\hline
\end{tabular}

Note: Questions 8 and 11 are reverse-scored so that a higher score indicates a more favorable response for all 14 items.

a Factor 1 = „Sexual Satisfaction“, factor 2 = „Confidence“, factor 3 = „Relational Satisfaction“

b Factor 1 = „Confidence“, factor 2 = „Sexual Functioning“, factor 3 = „Sexual Well-Being“

social desirability and have been more cautious about their disclosure of sexual issues.

\section{Factor structure of SEAR}

We were not able to replicate the two-factor structure (domains Sexual Relationship and Confidence) of SEAR in the original validation study [12]. This difference might be due to the different samples (men with erectile dysfunctions vs. infertile men and women without distinct sexual disorders). We found three stable factors for women and men, with different loading of the items. The interpretation of these different patterns is difficult. It seems that for women the relational aspects of sexuality were more important, whereas for men performance aspects were in the foreground. However, this interpretation may also be an expression of gender stereotypes.

\section{Strengths and limitations}

The strengths of our study are the large sample size of both men and women and measurement in a before-after design. Potential limitations are the retrospective design with a potential response bias concerning the evaluation of sexuality before the emergence of the desire for a child and also responses in line with social desirability. Future studies in this field should be done prospectively with measurements on sexuality, self-esteem and relationship satisfaction before the start of any infertility treatment and subsequent in the course of ART.

\section{Conclusions for Practice}

Infertility counselling could be facilitated by using instruments like SEAR for the identification of individuals whose infertility has a negative impact on their relationship quality and/or sex lives. These individuals will have most likely special needs in infertility counselling which should be addressed appropriately [17].

\section{Acknowledgments}

$\nabla$

We are grateful to the women and men who agreed to participate in this study.

\section{Conflict of Interest}

$\nabla$

The authors report no conflicts of interest and have no funding sources to disclose. The authors alone are responsible for the content and writing of the paper.

\section{References}

1 Cousineau TM, Domar AD. Psychological impact of infertility. Best Pract Res Clin Obstet Gynaecol 2007; 21: 293-308

2 El Kissi Y, Romdhane AB, Hidar S et al. General psychopathology, anxiety, depression and self-esteem in couples undergoing infertility treatment: a comparative study between men and women. Europ J Obstet Gynecol Reprod Biol 2013; 167: 185-189

3 Wischmann TH. Sexual disorders in infertile couples. J Sex Med 2010; 7: 1868-1876

4 Millheiser LS, Helmer AE, Quintero RB et al. Is infertility a risk factor for female sexual dysfunction? A case-control study. Fertil Steril 2010; 94: 2022-2025

5 Wischmann T. Sexual disorders in infertile couples: an update. Curr Opinion Obstet Gynecol 2013; 25: 220-222

6 Ferraresi SR, Lara LA, de Sa MF et al. Current research on how infertility affects the sexuality of men and women. Recent Pat Endocr Metab Immune Drug Discov 2013; 7: 198-202

7 Tao P, Coates $R$, Maycock $B$. The impact of infertility on sexuality: a literature review. Australasian Med J 2011; 4: 620-627

8 Monga M, Alexandrescu B, Katz SE et al. Impact of infertility on quality of life, marital adjustment, and sexual function. Urology 2004; 63: $126-130$

9 Schilling $K$, Toth B, Rösner S et al. Prevalence of behaviour-related fertility disorders in a clinical sample: results of a pilot study. Arch Gynecol Obstet 2012; 286: 1307-1314

10 Rosen RC, Riley A, Wagner $G$ et al. The International Index of Erectile Function (IIEF): A multidimensional scale for assessment of erectile dysfunction. Urology 1997; 49: 822-830

11 Rosen RC, Brown C, Heiman J et al. The Female Sexual Function Index (FSFI): a multidimensional self-report instrument for the assessment of female sexual function. J Sex Marital Ther 2000; 26: 191-208 
12 Cappelleri JC, Althof SE, Siegel RL et al. Development and validation of the Self-Esteem And Relationship (SEAR) questionnaire in erectile dysfunction. Int J Impot Res 2004; 16: 30-38

13 Nelson CJ, Shindel AW, Naughton CK et al. Prevalence and predictors of sexual problems, relationship stress, and depression in female partners of infertile couples. J Sex Med 2008; 5: 1907-1914

14 Mahlstedt PP. The psychological component of infertility. Fertil Steril 1985; 43: 335-346
15 Wischmann T, Thorn P. (Male) infertility: what does it mean to men? New evidence from quantitative and qualitative studies. Reprod BioMed Online 2013; 27: 236-243

16 Shindel AW, Nelson CJ, Naughton CK et al. Sexual function and quality of life in the male partner of infertile couples: prevalence and correlates of dysfunction. J Urol 2008; 179: 1056-1059

17 Peterson B, Boivin J, Norré J et al. An introduction to infertility counseling: a guide for mental health and medical professionals. J Assist Reprod Genetics 2012; 29: 243-248 